\title{
Comparative Metabolism of Mesoplasma, Entomoplasma, Mycoplasma, and Acholeplasma
}

\author{
J. DENNIS POLLACK, ${ }^{1 *}$ MARSHALL V. WILLIAMS,${ }^{1}$ JONATHAN BANZON, ${ }^{1}$ MELISSA A. JONES, ${ }^{1}$ \\ LINDA HARVEY, ${ }^{1}$ AND JOSEPH G. TULLY ${ }^{2}$ \\ Department of Medical Microbiology and Immunology, The Ohio State University, Columbus, Ohio 43210, ${ }^{1}$ \\ and Mycoplasma Section, National Institute of Allergy and Infectious Diseases, \\ Frederick Cancer Research Facility, Frederick, Maryland $21702^{2}$
}

\begin{abstract}
Cytoplasmic fractions from species of the Mollicutes genera Entomoplasma, Mesoplasma, Mycoplasma, and Acholeplasma were assayed for NADH oxidase (NADH ox), ATP- and PP -dependent phosphofructokinase (PFK), ATP- and $\mathbf{P P}_{\mathrm{i}}$-dependent deoxyguanosine kinase (dGUOK), thymidine kinase (TK), TMP kinase (TMPK), glucose-6-phosphate dehydrogenase (G6Pde), lactate dehydrogenase (LDH), malate dehydrogenase (MDH), phosphoenolpyruvate carboxylase, hypoxanthine-guanine phosphoribosyl transferase, dUTPase, and uracil-DNA glycosylase (UNG) activities. Membrane fractions were also examined for NADH ox activity. These activities were used as indicators of the presence and relative activities of major Mollicutes metabolic and DNA repair pathways. This was the first study to determine the presence of these enzymes in members of the genera Entomoplasma and Mesoplasma. Using the data obtained, we constructed a preliminary scheme for distinguishing genera of the class Mollicutes on the basis of the results of signature functional enzyme assays. This scheme includes phylogenetic relationships deduced from rRNA analyses, but is more informative with respect to metabolic potential. The criteria used include the presence of PP $_{\mathrm{i}}$-dependent PFK, urease, dUTPase, and dGUOK activities. Entomoplasma ellychniae $\mathbf{E L C N}-1^{\mathrm{T}}\left(\mathrm{T}=\right.$ type strain), Entomoplasma melaleucae $\mathbf{M - 1}^{\mathrm{T}}$, Mesoplasma seiffertii $\mathbf{F 7}^{\mathbf{T}}$, Mesoplasma entomophilum $\mathbf{T A C}^{\mathbf{T}}$, Mesoplasma florum $\mathbf{L 1}^{\mathbf{T}}$, Mycoplasma fermentans $\mathrm{PG18}^{\mathrm{T}}$, and Acholeplasma multilocale $\mathrm{PN525}^{\mathrm{T}}$ were similar in most respects. NADH ox activity was localized in the cytoplasm of these organisms. These strains had ATP-dependent PFK, MDH, LDH, ATP- and PP dependent dGUOK, and UNG activities, but not dUTPase or G6Pde activities. In contrast, Acholeplasma equifetale $\mathrm{C112}^{\mathrm{T}}$, Acholeplasma oculi $19 \mathrm{~L}^{\mathrm{T}}$, Acholeplasma hippikon $\mathrm{C1}^{\mathrm{T}}$, Acholeplasma modicum $\mathrm{PG}^{\mathrm{T}}{ }^{\mathrm{T}}$, and

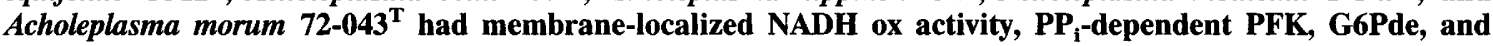
dUTPase activities, and significantly lower MDH and LDH activities and exhibited a faster rate with $P_{P_{i}}$ than with ATP in the dGUOK reaction. All of the members of the Mollicutes tested had hypoxanthine-guanine phosphoribosyl transferase, phosphoenolpyruvate carboxylase, and (except for Mesoplasma entomophilum TAC $^{\mathrm{T}}$ ) UNG activities. All of the Acholeplasma strains except Acholeplasma multilocale PN525 $^{\mathrm{T}}$ had TK, TMPK, and UNG activities. Mesoplasma entomophilum TAC $^{\mathrm{T}}$ was distinguished by having no detectable dUTPase, UNG, TK, and TMPK activities, indicating that there is a severe restriction in or an absence of a synthetic route to dTTP. Our data also suggest that $A$. multilocale PN525 $^{\mathrm{T}}$ is a member of an unrecognized metabolic subgroup of the genus Acholeplasma or is not an Acholeplasma strain.
\end{abstract}

Distinguishing members of the class Mollicutes by their metabolic characteristics has been of very limited phylogenetic and taxonomic usefulness. Standards for describing Mollicutes taxa have been published previously (7). Characteristics such as gross cellular morphology, colonial appearance, genome size, and serological relatedness are more frequently emphasized as discriminating features. There are a few metabolic exceptions, including the ability to hydrolyze urea exhibited by Ureaplasma species, the growth requirement for sterol of some members of the Mollicutes, and the requirement for anaerobiosis. The usefulness of the various discriminating characteristics is associated with the taxonomic level being distinguished. Pertinent distinguishing metabolic characteristics at the order and family levels are a requirement for sterols for growth, a requirement for anaerobiosis, and optimum temperature. At the genus level, the sterols necessary for growth, anaerobiosis, temperature, and urea hydrolysis are emphasized. At the species level, serological relatedness presently overshadows all other fea-

* Corresponding author. Mailing address: Department of Medical Microbiology and Immunology, The Ohio State University, 333 West 10th Ave., Columbus, OH 43210. Phone: (614) 292-8352. Fax: (614) 292-9805. Electronic mail address: pollack.1@osu.edu. tures, and genome size and $\mathrm{G}+\mathrm{C}$ content are recommended characteristics. Only rarely are fermentation of glucose and hydrolysis of arginine, esculin, and arbutin taxonomically consequential. Other discriminating metabolic activities have been described, but the usefulness of these characteristics suffers from the limited information about them for the approximately 150 known members of the Mollicutes $(21,26,28)$. In this study we examined what we characterize as signature functional enzymatic activities in two recently described genera of the class Mollicutes. The data which we obtained are combined with other data to form a taxonomic scheme at the generic level that is based on metabolism and that to some extent parallels the phylogenetic relatedness scheme for the genera determined by rRNA analyses $(30,35,42)$.

\section{MATERIALS AND METHODS}

Mollicutes, medium, and preparation of cytoplasmic and membrane fractions. The members of the Mollicutes included in this study are listed in Tables 1 through 3. The organisms were grown in 4-liter batches of SNE (26). All cultures were started with a 2 to $10 \%$ inoculum and were incubated at 30 or $37^{\circ} \mathrm{C}$ for $24 \mathrm{~h}$. Cells were harvested and washed in kappa buffer (25). In some experiments washed cell pellets were frozen at $-20^{\circ} \mathrm{C}$ for up to 4 months. Washed cells (fresh or thawed pellets) were broken by osmotic shock or sonication, and the resulting preparations were centrifuged to obtain membrane and cytoplasmic fractions as previously described (25). After the final centrifugation $(144,000 \times g, 2 \mathrm{~h})$, the 
TABLE 1. NADH ox specific activities of Mollicutes membrane and soluble (cytoplasmic) fractions

\begin{tabular}{|c|c|c|c|}
\hline \multirow[b]{2}{*}{ Strain } & \multicolumn{2}{|c|}{ NADH ox sp act ${ }^{a}$} & \multirow{2}{*}{$\mathrm{M} / \mathrm{S}^{b}$} \\
\hline & $\begin{array}{l}\text { Membrane } \\
\text { fraction }\end{array}$ & $\begin{array}{l}\text { Soluble } \\
\text { fraction }\end{array}$ & \\
\hline Entomoplasma ellychniae ELCN-1 ${ }^{\mathrm{T}}$ & $<0.001$ & $740 \pm 80$ & $<0.001$ \\
\hline Entomoplasma melaleucae $\mathrm{M}-1^{\mathrm{T}}$ & $<0.001$ & $1,120 \pm 81$ & $<0.001$ \\
\hline Mesoplasma seiffertii $\mathrm{F}^{\mathrm{T}}$ & $<0.001$ & $16 \pm 4$ & $<0.001$ \\
\hline Mesoplasma entomophilum $\mathrm{TAC}^{\mathrm{T}}$ & $<0.001$ & $724 \pm 61$ & $<0.001$ \\
\hline Mesoplasma florum $\mathrm{L1}^{\mathrm{T}}$ & 0.016 & $59 \pm 3$ & $<0.001$ \\
\hline Mesoplasma florum GF & 0.007 & $133 \pm 18$ & $<0.001$ \\
\hline Mycoplasma fermentans $\mathrm{PG} 8^{\mathrm{T}}$ & 0.020 & $11 \pm 1$ & 0.002 \\
\hline $\begin{array}{l}\text { Mycoplasma fermentans MI } \\
\text { (incognitus) }\end{array}$ & 0.009 & $4.1 \pm 0.4$ & 0.002 \\
\hline Acholeplasma equifetale $\mathrm{C} 112^{\mathrm{T}}$ & 142 & 10 & 14.2 \\
\hline Acholeplasma oculi $19 \mathrm{~L}^{\mathrm{T}}$ & 238 & 5 & 47.6 \\
\hline Acholeplasma multilocale $\mathrm{PN} 525^{\mathrm{T}}$ & $<0.001$ & $2.9 \pm 2.3$ & $<0.001$ \\
\hline Acholeplasma hippikon $\mathrm{C1}^{\mathrm{T}}$ & $\mathrm{NT}^{c}$ & 7 & \\
\hline Acholeplasma modicum $\mathrm{PG}_{4} 9^{\mathrm{T}}$ & 431 & 8 & 53.9 \\
\hline Acholeplasma morum $72-043^{\mathrm{T}}$ & NT & 10 & \\
\hline
\end{tabular}

${ }^{a}$ Specific activities are expressed as nanomoles of NADH consumed per minute per milligram of cytoplasmic or membrane protein. For some assays three different batches of cells were used, and the mean \pm standard deviation is given. If there is no standard deviation, the value is the mean of the values obtained with two different batches of cells. If activity could not be detected in two or three different batches of cells, the less than symbol is used and is followed by the lowest specific activity that could be detected by our assay.

${ }^{b} \mathrm{M} / \mathrm{S}$, ratio of membrane fraction specific activity to soluble (cytoplasmic) fraction specific activity.

${ }^{c} \mathrm{NT}$, not tested.

supernatant fractions were clarified by filtration through a $0.22-\mu \mathrm{m}$-pore-size filter to produce the final fraction (cytoplasmic fraction). Cell fractions were prepared at $4^{\circ} \mathrm{C}$. Membrane fractions were used only to assess NADH oxidase (NADH ox) activity.

Assays. The enzymatic assays used in this study were essentially identical to the standard pyrimidine-coupled spectrophotometric and radioisotopic assays that we have described previously. We performed assays for NADH ox (28), hexokinase (2), ATP- and PP-dependent phosphofructokinase (PFK) (29), glucose-6phosphate dehydrogenase (G6Pde) $(5,28)$, lactate dehydrogenase (LDH) $(16)$, phosphoenolpyruvate carboxylase (10), malate dehydrogenase (MDH) (9), hypoxanthine-guanine phosphoribosyl transferase (32), ATP- and $\mathrm{PP}_{\mathrm{i}}$-dependent deoxyguanosine kinase (dGUOK) (12), dUTPase (38), thymidine kinase (39), thymidine monophosphate kinase (TMPK) (8), and uracil DNA glycosylase (UNG) (40) activities.

\section{RESULTS}

The membrane fraction/soluble (cytoplasmic) fraction ratios indicate localization of activity; ratios higher than 0.3 indicate membrane localization, while lower values indicate soluble or cytoplasmic fraction localization $(21,22)$ (Table 1 ). We found that the NADH ox activities of Acholeplasma equifetale, Acholeplasma oculi, and Acholeplasma modicum were localized in the membrane fractions (Table 1). Acholeplasma multilocale PN525 $5^{\mathrm{T}}(\mathrm{T}=$ type strain) had a low level of NADH ox activity in its cytoplasmic fraction, and no activity was detected in the membrane fraction. The NADH ox activities of all other organisms examined were localized in the cytoplasmic fractions.

All of the Acholeplasma strains except $A$. multilocale PN525 had both hexokinase and G6Pde activities (Table 2). The $\mathrm{Me}$ soplasma strains and Mycoplasma fermentans did not have hexokinase activity. Mesoplasma florum GF had a relatively low level of G6Pde activity, and all other Mollicutes strains had no G6Pde activity.

All of the Acholeplasma strains except $A$. multilocale PN525 had PFK activity that was predominantly $\mathrm{PP}_{\mathrm{i}}$ dependent; i.e., the $\mathrm{PP}_{\mathrm{i}}$-dependent $\mathrm{PFK}$ activity was 10 - to 30 -fold greater than the ATP-dependent PFK activity (Table 2). On the other hand,

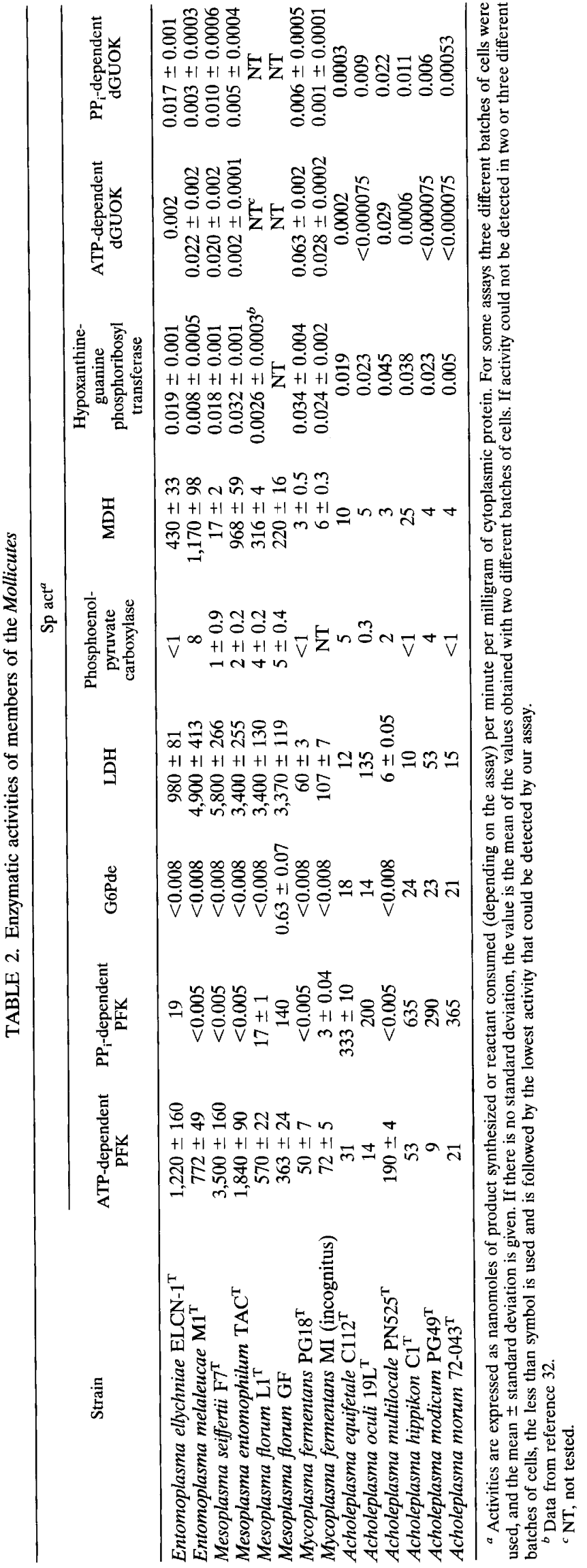


TABLE 3. Pyrimidine enzymatic activities of members of the Mollicutes

\begin{tabular}{|c|c|c|c|c|}
\hline \multirow{2}{*}{ Strain } & \multicolumn{4}{|c|}{ Sp act ${ }^{a}$} \\
\hline & dUTPase & Thymidine kinase & TMPK & UNG \\
\hline Entomoplasma ellychniae ELCN-1 ${ }^{\mathrm{T}}$ & $<1$ & $<0.001$ & $56 \pm 49$ & $0.316 \pm 0.073$ \\
\hline Entomoplasma melaleucae $\mathrm{M}^{\mathrm{T}}$ & $<1$ & $30 \pm 26$ & 85 & $0.275 \pm 0.114$ \\
\hline Mesoplasma seiffertii $\mathrm{F}^{\mathrm{T}}$ & $<1$ & $<0.001$ & $107 \pm 82$ & $<0.001$ \\
\hline Mesoplasma entomophilum TAC $^{\mathrm{T}}$ & $<1$ & $<0.001$ & $<0.001$ & $<0.001$ \\
\hline Mesoplasma florum $\mathrm{L}^{\mathrm{T}}$ & $<1$ & $0.3 \pm 0.2$ & $\mathrm{NT}^{b}$ & NT \\
\hline Mycoplasma fermentans $\mathrm{PG} 18^{\mathrm{T}}$ & $<1$ & $96 \pm 73$ & $124 \pm 115$ & 0.074 \\
\hline Mycoplasma fermentans MI (incognitus) & $<1$ & $0.3 \pm 0.1$ & $1.6 \pm 0.3$ & $0.436 \pm 0.058$ \\
\hline Acholeplasma equifetale $\mathrm{C} 112^{\mathrm{T}}$ & $15 \pm 11$ & $5.4 \pm 2.1$ & $65 \pm 59$ & $0.611 \pm 0.277$ \\
\hline Acholeplasma oculi $19 \mathrm{~L}^{\mathbf{T}}$ & $29 \pm 4$ & 2.8 & 43 & 0.352 \\
\hline Acholeplasma multilocale PN525 & $<1$ & 3.9 & 19 & $<0.001$ \\
\hline Acholeplasma hippikon $\mathrm{C}^{\mathrm{T}}$ & $0.7 \pm 0.2$ & 28 & 285 & 1.806 \\
\hline Acholeplasma modicum $\mathrm{PG} 49^{\mathrm{T}}$ & $2 \pm 0.1$ & 5 & 38 & 0.475 \\
\hline Acholeplasma morum $72-043^{\mathrm{T}}$ & $3 \pm 0.9$ & 7 & 21 & 0.233 \\
\hline
\end{tabular}

a Specific activities are expressed as nanomoles of product synthesized or reactant consumed (depending on the assay) per minute per milligram of cytoplasmic protein. For some assays three different batches of cells were used, and the mean \pm standard deviation is given. If there is no standard deviation, the value is the mean of the values obtained with two different batches of cells. If activity could not be detected in two or three different batches of cells, the less than symbol is used and is followed by the lowest specific activity that could be detected by our assay.

${ }^{b} \mathrm{NT}$, not tested.

A. multilocale PN525 ${ }^{\mathrm{T}}$, like the Entomoplasma, Mesoplasma, and Mycoplasma species, had ATP-dependent PFK activity. In most of these organisms the PFK specific activity with ATP was 1,000-fold greater than any $\mathrm{PP}_{\mathrm{i}}$-dependent specific activity. All of the members of the Mollicutes tested had LDH and MDH activities. It is worth noting that the levels of LDH and MDH activities in the Entomoplasma and Mesoplasma species were generally higher than the levels found in the other organisms, even though quantitative comparisons were not generally valuable in this study because our fractions were crude. Hypoxanthine-guanine phosphoribosyl transferase activity was detected in all strains, and phosphoenolpyruvate carboxylase activity was detected in most strains.

All of the Acholeplasma strains except $A$. multilocale PN525 had higher specific activities when $\mathrm{PP}_{\mathrm{i}}$ was used than when ATP was used in the dGUOK reaction (Table 2). No uniform preference for either ATP or $\mathrm{PP}_{\mathrm{i}}$ in the dGUOK reaction was observed with Mesoplasma and Entomoplasma strains. Both strains of Mycoplasma fermentans examined had higher specific activities in the dGUOK reaction when ATP was used than when $P_{P_{i}}$ was used.

dUTPase activity was found only in Acholeplasma species, but it was not found in $A$. multilocale PN525 $5^{\mathrm{T}}$ (Table 3 ). Thymidine kinase activity was detected in all of the strains tested except the Entomoplasma ellychniae, Mesoplasma entomophilum, and Mesoplasma seiffertii strains. TMPK activity was detected in all of the strains tested except the Mesoplasma entomophilum strain. UNG activity was found in all of the strains examined except the $A$. multilocale, Mesoplasma entomophilum, and Mesoplasma seiffertii strains.

\section{DISCUSSION}

Traditionally, identification and classification of members of the class Mollicutes have been based on phenotypic characteristics, such as the ability to produce acid from glucose, a requirement for urea for growth, and utilization or hydrolysis of arginine, on serological associations, and on rRNA sequences $(30,35)$. We suggest that assays for gene products (that is, functional enzyme assays) may be used with confidence to augment 16S rRNA gene analysis data to develop a simple and practical taxonomic scheme for identification and classification of members of the Mollicutes. Our concept is rooted in the view that the presence of enzymatic function is a reflection of inheritable traits and that an assay for function may be more informative for individual species than rRNA analysis or even primary gene sequence analysis when it is used alone.

Our suggestion is based on a series of observations. First, the members of the class Mollicutes have undergone a remarkable series of genome reductions regardless of the phylogenetic lineage, as determined by rRNA analysis $(30,35,42)$. As a result, this class of organisms contains some of the smallest genomes presently known among free-living organisms. This large-scale genome reduction has probably reduced the metabolic potential of these organisms in an as-yet unpredictable manner. Second, even when the complete genomic DNA sequence is known, the primary DNA sequence is not completely determinative with regard to function; that is, although function is dependent on the primary sequence, tertiary effects, such as the degree of oligomerization and peptide-peptide interactions, and the relative concentrations of substrates and cofactors also affect the function of the gene product. In addition, the extent of posttranslational modification of metabolic enzymes in prokaryotes other than modification through the action of toxins remains largely undescribed. Pancholi and Fischetti (18) have recently described the novel functional effects of ADP ribosylation of the glycolytic enzyme glyceraldehyde-3-phosphate dehydrogenase (GADPH) from group $A$ streptococci. It is also interesting that these researchers suggested earlier that GADPH (17) is exposed on the surface of group A streptococci and that through multiple binding capacities for human host proteins the members of a family of GADPH molecules may play different roles in the colonization, internalization, and proliferation of streptococci subject to minor sequence variations. Similarly, human GADPH has been shown to exhibit alternative enzymatic functions depending on its oligomeric state. For example, depending on the state of oligomerization, identical gene products may result in either GADPH activity or UNG activity (13).

In an alternative approach to our functional studies both Wasinger et al. (34), who analyzed Mycoplasma genitalium G37, and Cordwell et al. (3), who analyzed Spiroplasma melliferum, used a two-dimensional gel system to isolate and characterize specific proteins. Protein sequence data were compared with public database data to determine levels of 
TABLE 4. Distinguishing metabolic activities of genera of the class Mollicutes

\begin{tabular}{lccccc}
\hline \multirow{2}{*}{ Genus } & \multicolumn{5}{c}{ Enzyme activities } \\
\cline { 2 - 6 } & $\begin{array}{c}\mathrm{PP}_{\mathrm{i}^{-}} \\
\text {dependent } \\
\mathrm{PFK}\end{array}$ & Urease & dUTPase & $\begin{array}{c}\text { ATP- } \\
\text { dependent } \\
\text { dGUOK }\end{array}$ & $\begin{array}{c}\mathrm{PP}_{\mathrm{i}^{-}} \\
\text {dependent } \\
\text { dGUOK }\end{array}$ \\
\hline Acholeplasma & + & - & + & - & + \\
Anaeroplasma & + & - & + & - & + \\
Ureaplasma & - & + & - & - & - \\
Spiroplasma & - & - & + & + & $+^{a}$ \\
Mesoplasma $^{b}$ & $-c$ & - & - & Variable & Variable \\
Mycoplasma $^{b}$ & - & - & $-{ }^{d}$ & $-e$ & - \\
Entomoplasma $^{b}$ & - & - & - & Variable & Variable \\
Asteroleplasma & - & - & - & - & + \\
\hline
\end{tabular}

a Spiroplasma minum is $\mathrm{PP}_{\mathrm{i}}$-dependent dGUOK negative.

${ }^{b}$ Mesoplasma species can be distinguished from Mycoplasma and Entomoplasma species because Mesoplasma species grow on sterol-free media containing Tween 80, whereas Mycoplasma and Entomoplasma species do not (33). Provisionally, the UNG assay may be a discriminating assay, as the two Entomoplasma species have UNG activity and the two Mesoplasma do not (Table 3). Our data also indicate that Entomoplasma and Mesoplasma species have much higher MDH specific activities than Mycoplasma species.

${ }^{c}$ Mesoplasma flonum GF exhibits a low level of $\mathrm{PP}_{\mathrm{i}}$-dependent $\mathrm{PFK}$ activity.

${ }^{d}$ Mycoplasma mycoides subsp. mycoides is dUTPase positive (14) and exhibits phylogenetic and taxonomic affinity to the dUTPase-positive genus Spiroplasma $(35,36)$.

${ }^{e}$ Mycoplasma fermentans PG18 and MI are ATP-dependent dGUOK positive.

similarity and putative identity. This approach, however, emphasizes gene expression, not gene function, which must be assessed independently.

In the present study we found $\mathrm{MDH}$ activity in all Mesoplasma and Entomoplasma species tested. These findings extend our observation that except for the acholeplasmas, every member of the Mollicutes, including Mycoplasma genitalium $\mathrm{G37}^{\mathrm{T}}$ (9), has MDH activity $(9,20,23,27)$. However, no one has described a Mollicutes open reading frame or gene sequence that exhibits sufficient sequence homology to any MDH sequence or MDH consensus sequence in the data banks to claim identity or some level of similarity $(1,6,19)$. The MDH gene may be one of the gene sequences that have not been putatively assigned, perhaps because the open reading frames assigned to MDHs in other prokaryotes are insufficiently similar to Mollicutes sequences, as detected in multiple alignments. The supposed high mutability of the Mollicutes may be related to or the cause of an atypical gene sequence (40).

The data presented in this paper provide further evidence that six Mollicutes genera can be distinguished by their enzyme contents $(4,5,9,11,20,23,27)$. In addition, this study extended our previous findings to include species belonging to the two recently described genera of the class Mollicutes, the genera Entomoplasma and Mesoplasma (33). The total number of species in the eight genera that have been described is about 150 . Since we have studied only 66 species, including representatives of all eight genera, our comparative analysis is incomplete and the results are provisional. Using our data, we constructed a preliminary scheme, a scheme that was suggested in a recent report but was offered there without any supporting data (25); this scheme separates all of the Mollicutes genera on the basis of their enzyme contents and appears to be consistent with previous phylogenetic opinion at that level (30). The distinguishing enzymatic characteristics, based on this and other studies, are listed in Table 4 . In this arrangement the phylogenetically related members of the facultatively anaerobic genus Acholeplasma and the strictly anaerobic genus Anaeroplasma have indistinguishable characteristics.
The three Mesoplasma species and two Entomoplasma species that we examined had no dUTPase activity. We consider this remarkable, since before this study the only cells in nature that had been reported to lack dUTPase activity were the cells of members of the Mollicutes genera Mycoplasma, Ureaplasma, and Asteroleplasma $(20,37,38,40)$. The only exception within this group is the dUTPase-positive organism Mycoplasma mycoides subsp. mycoides, the type subspecies of the type species of the genus (14). However, this mycoplasma is now recognized as an organism that is more closely related phylogenetically to the dUTPase-positive spiroplasmas (35); the merits of retaining the name Mycoplasma mycoides subsp. mycoides for this organism rather than placing it in the genus Spiroplasma have been discussed previously (36).

Mesoplasma entomophilum $\mathrm{TAC}^{\mathrm{T}}$ is unusual in that it lacks not only UNG activity (UNG is a DNA repair enzyme), but also dUTPase, thymidine kinase, and TMPK activities. The absence of TMPK, represented by an inability to synthesize TDP, means that in order to gain TTP for DNA synthesis the organism must successfully scavenge for TDP or TTP itself. The ability to take up phosphorylated purines or pyrimidines (nucleoside diphosphates or nucleoside triphosphates) is relatively rare in prokaryotes, although it has been reported in Mycoplasma mycoides subsp. mycoides (15). The absence of UNG and dUTPase suggests that this organism may have a higher incidence of mutations involving either the incorporation of dUTP into DNA or an apparent inability to excise uracil from its DNA (39-41).

The relatively high levels of ATP-dependent PFK, LDH, and MDH and the absence of G6Pde activities in the Entomoplasma and Mesoplasma species suggest that the members of these genera rely on glycolysis and are fermentative. Also, they may not be capable of ribose synthesis via the pentose phosphate pathway and may be dependent on the maintenance of intracellular NAD concentrations and NADH ox activity to maintain LDH and $\mathrm{MDH}$ activities or other reactions involving the terminal transfer of electrons.

Of interest is our observation that two human isolates of Mycoplasma fermentans, the Mycoplasma species associated with AIDS, have ATP-dependent nucleoside kinase activity. One of our isolates, Mycoplasma fermentans MI, was originally isolated from an AIDS patient. We have shown that all Mycoplasma strains except certain Mycoplasma hominis strains are unable to phosphorylate any nucleoside tested to form the respective nucleoside monophosphate $(31,32)$. Four strains isolated from humans with clinical symptoms of disease exhibited nucleoside kinase activity, but these strains used $\mathrm{PP}_{\mathrm{j}}$, not ATP, as the phosphorus donor (11). Four nonhuman isolates could not phosphorylate nucleosides with either ATP or $\mathrm{PP}_{\mathrm{i}}$. On the other hand, the relatively common human Mollicutes pathogen Mycoplasma pneumoniae and two organisms frequently associated with human disease, Mycoplasma genitalium and Ureaplasma urealyticum, have no detectable nucleoside kinase activity (11). The significance of the association of nucleoside phosphorylation in only some strains isolated from patients with clinical disease is not known, but we feel that this association deserves further study.

A. multilocale PN525 ${ }^{\mathrm{T}}$ was found to lack hexokinase, G6Pde, PP $_{\mathrm{i}}$-dependent PFK, dUTPase, and UNG activities and could use both ATP and $\mathrm{PP}_{\mathrm{i}}$ in the dGUOK reaction. This isolate lacked membrane-associated NADH ox activity and cannot reduce benzyl viologen (26). All of these responses are unlike those found in any of the other 12 known Acholeplasma species $(5,9-12,26-29)$. These differences represent aberrations in the following six metabolic pathways: glycolysis, pentose phosphate, pyrimidine and purine metabolism, DNA repair, and 
respiration. We suggest that $A$. multilocale $\mathrm{PN} 525^{\mathrm{T}}$ is a member of an unrecognized metabolic subgroup of the genus Acholeplasma or is not an Acholeplasma strain. The bulk of our data suggests that $A$. multilocale PN525 $5^{\mathrm{T}}$ is either a Mycoplasma strain or an Entomoplasma strain.

$\mathrm{NADH}$ ox activity is localized in the membrane of almost every prokaryote. Acholeplasma species also have this characteristic, but Mycoplasma, Spiroplasma, and Ureaplasma species are known to be exceptions $(21-23,27)$. The localization of NADH ox activity in the cytoplasmic fraction of the Mesoplasma and Entomoplasma species examined in this study metabolically relates these genera to the genera Mycoplasma, Spiroplasma, and Ureaplasma. The Mollicutes strain formerly called Acholeplasma florum L1 and now called Mesoplasma florum $\mathrm{L1}^{\mathrm{T}}$ initially disrupted the concept that all Acholeplasma species had membrane-localized NADH ox activity since the activity in this organism was found to be localized in the cytoplasm (24). In the present study we confirmed this observation. However, with the reassignment of this species to the genus Mesoplasma (33) the remaining Acholeplasma species tested are the only Mollicutes species with membranelocalized NADH ox activity, and the concept that membrane localization of NADH ox activity can be used to identify Acholeplasma species is supported.

\section{ACKNOWLEDGMENTS}

This study was supported by Public Health Service grant RO1A133193 from the National Institutes of Health.

We thank Maria Ariza for technical assistance with the analysis of enzymes involved in pyrimidine deoxynucleotide biosynthesis and Roger Miles and Victor V. Tryon for valuable criticisms and helpful suggestions.

\section{REFERENCES}

1. Bork, P., C. Ouzounis, G. Casari, R. Schneider, C. Sander, M. Dolan, W. Gilbert, and P. M. Gillivet. 1995. Exploring the Mycoplasma capricolum genome: a minimal cell reveals its physiology. Mol. Microbiol. 16:955-987.

2. Chou, A. C., and J. E. Wilson. 1975. Hexokinase from rat brain. Methods Enzymol. 42:20-25.

3. Cordwell, S. J., M. R. Wilkins, A. Cerpa-Poljak, A. A. Gooley, M. Duncan, K. L. Williams, and I. Humphery-Smith. 1995. Cross-species identification of proteins separated by two-dimensional gel electrophoresis using matrixassisted laser desorption ionisation/time-of-flight mass spectrometry and amino acid composition. Electrophoresis 16:438-443.

4. Davis, J. W., Jr., J. T. Manolukas, B. E. Capo, and J. D. Pollack. 1990. Pyruvate metabolism and the absence of a tricarboxylic acid cycle in Ureaplasma urealyticum. Zentralbl. Bakteriol. Suppl. 20:666-669.

5. Desantis, D., V. V. Tryon, and J. D. Pollack. 1989. Metabolism of the mollicutes: the Embden-Meyerhof-Parnas pathway and the hexose monophosphate shunt. J. Gen. Microbiol. 135:683-691.

6. Fraser, C. M., J. D. Gocayne, O. White, M. D. Adams, R. A. Clayton, R. D. Fleischmann, C. J. Bult, A. R. Kerlavage, G. Sutton, J. M. Kelley, J. L. Fritchman, J. F. Weidman, K. V. Small, M. Sandusky, J. Fuhrmann, D. Nguyen, T. R. Utterback, D. M. Saudek, C. A. Phillips, J. M. Merrick, J.-F. Tomb, B. A. Dougherty, K. F. Bott, P.-C. Hu, T. S. Lucier, S. N. Peterson, H. O. Smith, C. A. Hutchison III, and J. C. Venter. 1995. The Mycoplasma genitalium genome sequence reveals a minimal gene complement. Science 270:397-403.

7. International Committee on Systematic Bacteriology Subcommittee on the Taxonomy of the Mollicutes. 1995. Proposal for minimum standards for descriptions of new species of the class Mollicutes. Int. J. Syst. Bacteriol. 45:605-612.

8. Lee, L.-S., and Y.-C. Cheng. 1977. Human thymidylate kinase. Purification, characterization and kinetic behaviour of the thymidylate kinase derived from chronic myelocytic leukemia. J. Biol. Chem. 252:5686-5691.

9. Manolukas, J. T., M. F. Barile, D. K. F. Chandler, and J. D. Pollack. 1988. Presence of anaplerotic reactions and transamination, and the absence of the tricarboxylic acid cycle in mollicutes. J. Gen. Microbiol. 134:791-800.

10. Manolukas, J. T., M. V. Williams, and J. D. Pollack. 1989. The anaplerotic phosphenolpyruvate carboxylase of the tricarboxylic acid cycle deficient Acholeplasma laidlawii B-PG9. J. Gen. Microbiol. 135:251-256.

11. McElwain, M. C., D. K. F. Chandler, M. F. Barile, T. F. Young, V. V. Tryon, J. W. Davis, Jr., J. P. Petzel, C.-J. Chang, M. V. Williams, and J. D. Pollack.
1988. Purine and pyrimidine metabolism in mollicutes species. Int. J. Syst. Bacteriol. 38:417-423.

12. McElwain, M. C., and J. D. Pollack. 1987. Synthesis of deoxymononucleotides in mollicutes: dependence on deoxyribose-1-phosphate and $\mathbf{P P}_{\mathrm{i}}$. J. Bacteriol. 169:3647-3653.

13. Meyer-Siegler, K., D. J. Mauro, G. Seal, J. Wurzer, J. K. deRiel, and M. A. Sirover. 1991. A human nuclear uracil DNA glycosylase is the $37-\mathrm{kDa}$ subunit of glyceraldehyde-3-phosphate dehydrogenase. Proc. Natl. Acad. Sci. USA 88:8460-8464.

14. Neale, G. A. M., A. Mitchell, and L. R. Finch. 1983. Pathways of pyrimidine deoxyribonucleotide biosynthesis in Mycoplasma mycoides subsp. mycoides. J. Bacteriol. 154:17-22.

15. Neale, G. A. M., A. Mitchell, and L. R. Finch. 1984. Uptake and utilization of deoxynucleoside 5'-monophosphates by Mycoplasma mycoides subsp. mycoides. J. Bacteriol. 158:943-947.

16. Neimark, H. C., and R. Lemcke. 1972. Occurrence and properties of lactic dehydrogenase of fermentative mycoplasmas. J. Bacteriol. 111:633-640.

17. Pancholi, V., and V. A. Fischetti. 1992. A major surface protein on group A streptococci is a glyceraldehyde-3-phosphate-dehydrogenase with multiple binding activity. J. Exp. Med. 176:415-426.

18. Pancholi, V., and V. A. Fischetti. 1993. Glyceraldehyde-3-phosphate dehydrogenase on the surface of a group A streptococci is also an ADP-ribosylating enzyme. Proc. Natl. Acad. Sci. USA 90:8154-8158.

19. Peterson, S. N., T. Lucier, K. Heitzman, E. A. Smith, K. F. Bott, P.-C. Hu, and C. A. Hutchison III. 1995. Genetic map of the Mycoplasma genitalium chromosome. J. Bacteriol. 177:3199-3204.

20. Petzel, J. M., M. C. McElwain, D. Desantis, J. Manolukas, M. V. Williams, P. A. Hartman, M. J. Allison, and J. D. Pollack. 1989. Enzymic activities of carbohydrate, purine, and pyrimidine metabolism in the Anaeroplasmataceae (class Mollicutes). Arch. Microbiol. 152:309-316.

21. Pollack, J. D. 1975 . Localization of reduced nicotinamide adenine dinucleotide oxidase activity in Acholeplasma and Mycoplasma species. Int. J. Syst. Bacteriol. 25:108-113.

22. Pollack, J. D. 1979. Respiratory pathways and energy yielding mechanisms, p. 187-211. In M. F. Barile and S. Razin (ed.), The mycoplasmas, vol. 1. Academic Press, Inc., New York.

23. Pollack, J. D. 1986. Metabolic distinctiveness of ureaplasmas. Pediatr. Infect. Dis. 5:S305-S307.

24. Pollack, J. D. 1992. Carbohydrate metabolism and energy conservation, p. 181-200. In J. Maniloff, R. N. McElhaney, L. R. Finch, and J. B. Baseman, (ed.), Mycoplasmas: molecular biology and pathogenesis. American Society for Microbiology, Washington, D.C.

25. Pollack, J. D. 1995. Methods for testing metabolic activities in mollicutes, p. 277-286. In S. Razin and J. G. Tully (ed.), Molecular and diagnostic procedures for mycoplasmology, vol. 1. Academic Press, Inc., New York.

26. Pollack, J. D., J. Banzon, K. Donelson, J. G. Tully, J. W. Davis, Jr., K. J. Hackett, C. Agbanyim, and R. J. Miles. 1996. Reduction of benzyl viologen distinguishes genera of the class Mollicutes. Int. J. Syst. Bacteriol. 46:881884.

27. Pollack, J. D., M. C. McElwain, D. Desantis, J. T. Manolukas, J. G. Tully, C.-J. Chang, R. F. Whitcomb, K. J. Hackett, and M. V. Williams. 1989. Metabolism of members of the Spiroplasmataceae. Int. J. Syst. Bacteriol. 39:406-412.

28. Pollack, J. D., S. Razin, and R. C. Cleverdon. 1965. Localization of enzymes in Mycoplasma. J. Bacteriol. 90:617-622.

29. Pollack, J. D., and M. V. Williams. 1986. $\mathrm{PP}_{\mathrm{i}}$-dependent phosphofructotransferase (phosphofructokinase) activity in the mollicutes (mycoplasma) Acholeplasma laidlawii. J. Bacteriol. 165:53-60.

30. Rogers, M. J., J. Simmons, R. T. Walker, W. G. Weisburg, C. R. Woese, R. S. Tanner, I. M. Robinson, D. A. Stahl, G. Olsen, R. H. Leach, and J. Maniloff. 1985. Construction of the mycoplasma evolutionary tree from 5S rRNA sequence data. Proc. Natl. Acad. Sci. USA 82:1160-1164.

31. Tryon, V. V., and J. D. Pollack. 1984. Purine metabolism in Acholeplasma laidlawii B-PG9: novel $\mathrm{PP}_{\mathrm{i}}$-dependent nucleoside kinase activity. J. Bacteriol. 159:265-270.

32. Tryon, V. V., and J. D. Pollack. 1985. Distinctions in Mollicutes purine metabolism: pyrophosphate-dependent nucleoside kinase and dependence on guanylate salvage. Int. J. Syst. Bacteriol. 35:497-501.

33. Tully, J. G., J. M. Bové, F. Laigret, and R. F. Whitcomb. 1993. Revised taxonomy of the class Mollicutes: proposed elevation of a monophyletic cluster of arthropod-associated mollicutes to ordinal rank (Entomoplasmatales ord. nov.) with provision for familial rank to separate species with nonhelical morphology (Entomoplasmataceae fam. nov.) from helical species (Spiroplasmataceae), and emended descriptions of the order Mycoplasmatales, family Mycoplasmataceae. Int. J. Syst. Bacteriol. 43:378-385.

34. Wasinger, V. C., S. J. Cordwell, A. Cerpa-Poljak, J. X. Yan, A. A. Gooley, M. R. Wilkins, M. W. Duncan, R. Harris, K. L. Williams, and I. HumpherySmith. 1995. Progress with gene-product mapping of the mollicutes: Mycoplasma genitalium. Electrophoresis 16:1090-1094.

35. Weisburg, W. G., J. G. Tully, D. L. Rose, J. P. Petzel, H. Oyaizu, D. Yang, L. Mandeico, J. Sechrest, T. G. Lawrence, J. VanEtten, J. Manilof, and C. R. Woese. 1989. A phylogenetic analysis of the mycoplasmas: basis for their 
classification. J. Bacteriol. 171:6455-6467.

36. Whitcomb, R. F., and K. J. Hackett. 1989. Why are there so many species of Mollicutes? An essay on prokaryote diversity, p. 205-240. In L. Knutson and A. K. Stoner (ed.), Biotic diversity and germ plasm preservation, global imperative. Kluwer Academic Publishers, Dordrecht, The Netherlands.

37. Williams, M. V., and J. D. Pollack. 1984. Purification and characterization of a dUTPase from Acholeplasma laidlawii B-PG9. J. Bacteriol. 159:278282.

38. Williams, M. V., and J. D. Pollack. 1985. Pyrimidine deoxyribonucleotide metabolism in Acholeplasma laidlawii B-PG9. J. Bacteriol. 161:1029-1033.

39. Williams, M. V., and J. D. Pollack. 1988. Uracil-DNA glycosylase activity.
Relationship to proposed biased mutation pressure in the class mollicutes, $p$. 440-444. In R. E. Moses and W. C. Summers (ed.), DNA replication and mutagenesis. American Society for Microbiology, Washington, D.C.

40. Williams, M. V., and J. D. Pollack. 1990. A mollicute (mycoplasma) DNA repair enzyme: purification and characterization of uracil-DNA glycosylase. J. Bacteriol. 172:2979-2985.

41. Williams, M. V., and J. D. Pollack. 1990. The importance of differences in the pyrimidine metabolism of the mollicutes. Zentralbl. Bakteriol. Suppl. 20:163-171.

42. Woese, C. R., J. Maniloff, and L. B. Zablen. 1980. Phylogenetic analysis of the mycoplasmas. Proc. Natl. Acad. Sci. USA 77:494-498. 